\title{
Genetic parameters for reproductive traits in a beef cattle herd estimated using multitrait analysis
}

\author{
R.R. van der Westhuizen ${ }^{1 \#}$, S.J. Schoeman ${ }^{1}$, G.F. Jordaan ${ }^{1}$ and J.B. van Wyk ${ }^{2}$ \\ ${ }^{1}$ Department of Animal Science, University of Stellenbosch, Private Bag X1, Matieland 7602, South Africa \\ ${ }^{2}$ Department of Animal Science, University of the Orange Free State; P O Box 339, Bloemfontein 9300, South Africa
}

\begin{abstract}
The object of this study was to estimate heritabilities and genetic correlations for reproductive traits in a composite multibreed beef cattle herd using multitrait analysis. A REML procedure fitting a multitrait animal model was used to analyse data. Heritabilities and genetic correlations for calving interval (CI), calving date (CD), calving date with a penalty score (CDP) and age at first calving (AFC) were estimated as traits of the dam. The estimated heritabilities for CI, CD, CDP and AFC obtained in this study were 0.01, $0.04,0.06$ and 0.40 respectively with a repeatability of $0.07,0.12$ and 0.13 for CI, CD and CDP. Genetic correlations between traits varied from low to moderate, except for high correlations between CD and CDP (0.98), CI and CD (0.75) and between CI and CDP (0.79). Heritabilities, genetic correlations and repeatabilities of $\mathrm{CD}$ and $\mathrm{CDP}$ obtained in this study suggest that CD and CDP are the same traits and that selection for CDP rather then for $\mathrm{CD}$ does not have any additional advantages. Due to the additional advantages of $\mathrm{CD}$ over $\mathrm{CI}$ and the fact that $\mathrm{CD}$ is a less biased measurement of the female reproductive complex, CD and AFC (because of its high heritability) may be considered as selection criteria for improvement of reproduction in beef cattle herds.
\end{abstract}

Keywords: beef cattle, breeding, genetics, heritability, reproduction

1\# Author to whom correspondence should be addressed; present address: ARC-Animal Improvement Institute, Private Bag X2, Irene, 0062, South Africa; e-mail: bobbie@idpi1.agric.za

\section{Introduction}

Reproduction is a complex trait with many components. Measures of reproductive performance used as selection criteria include calving interval (CI), calving rate, services per conception, age at first calving (AFC), days to calving and calving date (CD) (Meaker et al., 1980; Bourdon \& Brinks, 1983; Meyer et al., 1990; Rege \& Famula, 1993; Van der Merwe \& Schoeman, 1995). Calving interval has traditionally been used as the preferred measure of reproduction, particularly in dairy cattle systems (Rege \& Famula, 1993). However, because a relatively short breeding season is usually employed in beef cattle systems, CI has limited value as a selection criterion. For this reason, calving date is considered to be more suitable (Bourdon \& Brinks, 1983).

In South Africa, the National Beef Cattle Improvement Scheme processes production data collected from farmers for use by the farmers for selection. Age at first calving and CI are most frequently used to evaluate reproductive performance. However, beef cattle are mostly mated during a limited breeding season. Bourdon \& Brinks (1983), Marshall et al. (1990) and MacGregor (1995) have found CI to be a biased measure of reproductive performance due to its negative association with previous calving date (PCD), as cows that calve early in the season have the longest subsequent CI. For various reasons, Bourdon \& Brinks (1983), Buddenberg et al. (1990), Lòpez de Torre \& Brinks (1990), Marshall et al. (1990) and MacGregor (1995) suggested that $C D$ should be used as the preferred measurement of reproduction for restricted breeding seasons. These reasons include lower birth weights, reduced incidence of dystocia, higher weaning and yearling weights and higher reconception rates.

Reducing the age at first calving is one way of improving lifetime efficiency in the beef cow (Van der Merwe \& Schoeman, 1995). In general, beef heifers are managed to calve for the first time at three years of age. However, first-year mating of heifers has been advocated (Fahmy et al., 1971; Meaker et al., 1980; Nunez-Dominguez et al., 1991) and applied in many herds, including the one under investigation. The advantage of mating heifers one year earlier lies in the potential increase in lifetime production of an extra calf (Meaker et al., 1980). Most published heritabilities for age at first calving are low (Toelle \& Robison 1985; Smith et al., 1989; Frazier et al., 1999) and indicate that age at first calving depends on nutrition and management. Most of these estimates were obtained by using unitrait analysis. The objectives of this study 
were to assess and to estimate heritabilities for and genetic correlations between CI, CD and AFC in a multibreed beef cattle herd using multitrait analysis, and to evaluate a penalty effect for CD.

\section{Materials and Methods}

Data used in this study were obtained from the multibreed beef cattle herd of the Johannesburg Metropolitan Council. The animals were kept on two farms in an intensive management system (Paterson, 1981; MacGregor, 1997). The herd was established in 1962 when several crossbreeding experiments were initiated involving Hereford, Angus, Simmentaler, Charolais, Sussex, Brahman, Bonsmara, Afrikaner and Holstein sires that were mainly used on Afrikaner, Hereford and Bonsmara cows. These crossbred groups were subsequently pooled. The breed genotype of these animals is complicated (Paterson, 1981; MacGregor, 1997) and 352 breed genotypes have been identified. Females were bred using AI mainly during two restricted breeding seasons of approximately three to four months each, although a few cows also calved out of season. They were normally inseminated between September and December to calve between June and September of the following year. Animals that did not conceive during this breeding period were inseminated for a second time between May and July. Most (92\%) of the females calved between June and September, $2 \%$ calved between October and January, while $6 \%$ calved in the second calving season between February and May.

Eighty one percent of all females that gave birth during the second calving season were first-calving heifers. Heifers that did not conceive during the first AI season were re-bred and calved at two and a half years of age. Because of this, only cow records were used in the analysis of calving interval, calving date and calving date with a penalty score. Month of calving varied from June to October. The data set contained 32691 observations from 13049 females. There were 25684 animals in the pedigree file.

Calving interval (CI) was calculated as the interval between successive calving dates. The mean CI from 22799 records was $390.7( \pm 71.72)$ days. In this study calving date (CD) was used in preference to days to calving (DC), as the date of first joining for each female was unknown. Calving date was recorded as the number of days from the onset of the first calving season (1 June) until the dam calved. Previous calving dates (PCD) were also recorded. The mean CD was $79.3( \pm 20.31)$ days, which indicates that the majority of cows calved fairly early in calving season. The number of CD records was 22465 . Since a number of cows failed to calve each year, a penalty score was assigned to those females. The cow having the highest $C D$ value in a specific year was identified and 21 days were then added to her CD value. Penalty score values assigned to non-calvers varied between years from zero in 1984, when all cows calved, to 336 days in 1979 to 1981 . The mean calving date value with the penalty score added (CDP) was $88.3( \pm 31.12)$ days with 25440 calving dates recorded.

Mean age at first calving (AFC) of 7251 heifer records was $781.8( \pm 119.60)$ days. Most of those which failed to calve for the first time at approximately 2 years were culled, while some were retained in the herd and were rebred in the following breeding season.

A linear regression procedure of $\mathrm{CI}$ on $\mathrm{CD}, \mathrm{CD}$ on $\mathrm{PCD}$ and $\mathrm{CI}$ on $\mathrm{PCD}$ was performed using the PROC REG procedure of SAS (1993) because CI is negatively associated with previous calving date (PCD) (Bourdon \& Brinks, 1983; Buddenberg et al., 1990; Lòpez de Torre \& Brinks, 1990; Marshal et al., 1990; MacGregor, 1995). For the estimation of (co)variance components for AFC, CD, CDP and CI, a restricted maximum likelihood procedure fitting a multitrait animal model (using the REML VCE 4.2.5 package of Groeneveld, 1998) was used to analyse the data. Traits were considered as traits of the dam, and a repeatability model was fitted due to the repeatable nature of these traits. To determine the importance of possible non-genetic sources of variation on CI, CD, CDP and AFC, the following fixed effects were fitted into the initial model using the PROC GLM procedure of SAS (1993): the herd-birth year concatenation (HY) (46 levels), production year of the dam (14 levels) and genotype (352 levels), while the age of the cow was included as a covariate. Mean age of dams was $5.3( \pm 2.78)$ years. Genotypes of the females were obtained form Skrypzeck et al. (2000). The following model was used for analysis:

$$
\begin{aligned}
& \mathbf{y}=\mathrm{Xb}+\mathrm{Za}+\mathbf{e} \\
& \mathbf{y}=\text { a vector of observations for the } i^{\text {th }} \text { trait, } \\
& \text { b }=\text { a vector of fixed effects of the } \mathrm{i}^{\text {th }} \text { trait, } \\
& \text { a }=\text { a vector of random animal effects of } i^{\text {th }} \text { trait, } \\
& \text { e }=\text { a vector of random residual effects of the } \mathrm{i}^{\text {th }} \text { trait and } \\
& \mathrm{X} \text { and } \mathrm{Z}=\text { incidence matrixes relating records of the } \mathrm{i}^{\text {th }} \text { trait to fixed and random animal } \\
& \text { effects, respectively. }
\end{aligned}
$$


Model specifications for the four traits AFC, CI, CD and CDP in the initial models are presented in Table 1. For the operational models those effects having no influence $(\mathrm{P}<0.05)$ on the traits were subsequently removed.

Table 1 Effects and covariable included in initial statistical models for AFC, CI, CD and CDP

\begin{tabular}{|c|c|c|c|c|c|c|}
\hline \multirow[t]{2}{*}{ Effect } & \multirow[t]{2}{*}{ *Type } & \multirow{2}{*}{$\begin{array}{c}\text { Number of } \\
\text { levels }\end{array}$} & \multicolumn{4}{|c|}{ Trait } \\
\hline & & & $\mathrm{AFC}$ & $\mathrm{CI}$ & $\mathrm{CD}$ & CDP \\
\hline Herd & $\mathrm{F}$ & 2 & $\mathrm{x}$ & & & \\
\hline Herd - year of birth & $\mathrm{F}$ & $45-47$ & & $\mathrm{x}$ & $\mathrm{x}$ & $\mathrm{x}$ \\
\hline Production year & $\mathrm{F}$ & 14 & $\mathrm{x}$ & $\mathrm{x}$ & $\mathrm{x}$ & $\mathrm{x}$ \\
\hline Genotype & $\mathrm{F}$ & $256-352$ & $\mathrm{x}$ & $\mathrm{x}$ & $\mathrm{x}$ & $\mathrm{x}$ \\
\hline Dam age & $\mathrm{C}$ & 7 & $\mathrm{x}$ & $\mathrm{x}$ & $\mathrm{x}$ & $\mathrm{x}$ \\
\hline
\end{tabular}

*F - fixed, C - covariable

\section{Results and Discussion}

Analyses of variance for the effects included in the operational models are presented in Table 2 (AFC and $\mathrm{CI}$ ) and Table 3 (CD and CDP). The $\mathrm{R}^{2}$ value was very low for $\mathrm{CI}$ but much higher for AFC, where the model fits the data fairly well. The low $\mathrm{R}^{2}$ values for reproductive traits could be due to the composite nature of the female reproductive traits or to the large influence of unidentified environmental effects on reproductive performance.

Table 2 Analyses of variance for AFC and CI

\begin{tabular}{|c|c|c|c|c|c|c|}
\hline \multirow[t]{2}{*}{ Non-genetic source } & \multicolumn{3}{|c|}{ Age at first calving } & \multicolumn{3}{|c|}{ Calving Interval } \\
\hline & $\mathrm{df}$ & Mean Square & $\operatorname{Pr}>F$ & $\mathrm{df}$ & Mean Square & $\operatorname{Pr}>\mathrm{F}$ \\
\hline HY & & & & & & \\
\hline Production year & 13 & 527241.69 & 0.0001 & 46 & 19275.32 & 0.0001 \\
\hline Genotype & 255 & 2854.36 & 0.0001 & 13 & 80546.30 & 0.0001 \\
\hline $\mathrm{R}^{2}$ & \multicolumn{3}{|c|}{0.79} & \multicolumn{3}{|c|}{0.10} \\
\hline
\end{tabular}

Table 3 Analyses of variance for CD and CDP

\begin{tabular}{|c|c|c|c|c|c|c|}
\hline \multirow{2}{*}{ Non-genetic source } & \multicolumn{3}{|c|}{ Calving Date } & \multicolumn{3}{|c|}{ Calving date (penalty score) } \\
\hline & $\mathrm{df}$ & Mean Square & $\operatorname{Pr}>\mathrm{F}$ & $\mathrm{df}$ & Mean Square & $\operatorname{Pr}>\mathrm{F}$ \\
\hline $\mathrm{HY}$ & 44 & 49061.51 & 0.0001 & 44 & 50248.96 & 0.0001 \\
\hline Production year & 13 & 2195.49 & 0.0001 & 13 & 32905.96 & 0.0001 \\
\hline Genotype & 351 & 404.22 & 0.0001 & 348 & 893.51 & 0.0001 \\
\hline $\mathrm{R}^{2}$ & \multicolumn{3}{|c|}{0.36} & \multicolumn{3}{|c|}{0.21} \\
\hline
\end{tabular}

In the cases of all four traits production year had an effect $(\mathrm{P} \leq 0.0001)$ and explained a large percentage of the total variance. The same applied to the herd-birth year (HY) concatenation. Although three of the four traits were also influenced by genotype $(\mathrm{P} \leq 0.0001)$, only a small proportion of the total variance was accounted for $(0.10,0.05$ and $0.07 \%$ for $\mathrm{AFG}, \mathrm{CD}$ and $\mathrm{CDP}$, respectively). Because of the large number of genotypes (256, 352 and 349 for AFC, CD and CDP, respectively) the least-squares means are not presented or discussed in this paper.

Regression equations and descriptive statistics for the reproductive traits are presented in Table 4. Although there is strong evidence $(\mathrm{P} \leq 0.0001)$ of a relationship between the different traits, $\mathrm{r}^{2}$ values were fairly small, indicating relatively poor fit. 
Table 4 Regression equations and descriptive statistics for reproductive traits

\begin{tabular}{cclccc}
\hline \multirow{2}{*}{$\begin{array}{c}\text { Traits } \\
\text { vependent }\end{array}$} & $\begin{array}{c}\text { Independent } \\
\text { variable }\end{array}$ & Equation & $* \mathrm{n}$ & Significance & $\mathrm{r}^{2}$ \\
\hline CI & CD & $\mathrm{y}=326.2+0.58 \mathrm{x}$ & 22465 & $\mathrm{P} \leq 0.0001$ & 0.10 \\
CD & PCD & $\mathrm{y}=47.0+0.43 \mathrm{x}$ & 22465 & $\mathrm{P} \leq 0.0001$ & 0.19 \\
CI & PCD & $\mathrm{y}=405.7-0.45 \mathrm{x}$ & 20714 & $\mathrm{P} \leq 0.0001$ & 0.12 \\
\hline
\end{tabular}

*number of observations

Cows that calved late in a year also tend to calve late in the subsequent year. In this study CD was delayed by 0.43 days for each day delay in the PCD. In most other comparable studies lower estimates in the order of 0.11 to 0.18 days were obtained (Bourdon \& Brinks, 1983; Morris \& Cullen, 1988; MacGregor, 1995). It was also shown that cows that calved earlier in a year had longer calving intervals in the subsequent year. Calving interval was reduced by 0.45 days for each one-day delay in previous calving date. It is well known that $\mathrm{CI}$ is a biased measure of reproductive performance in a restricted breeding season due to its negative association with previous calving date (PCD) (Bourdon \& Brinks, 1983; Marshall et al., 1990; MacGregor, 1995). Direct selection for a shorter CI could therefore result in indirect selection for later calving, since cows with the shortest CI are often those that calved late in the previous calving season. In several other studies (Bourdon \& Brinks, 1983; Lishman et al., 1984; Morris, 1984; Marshall et al., 1990; Rege \& Formula, 1993), a decrease in CI was also reported for each day delay in the previous calving date. Bourdon \& Brinks (1983) found that calving interval was reduced by 0.86 days for each one-day delay in previous calving date. Likewise, Morris (1984) found regression coefficients of 0.70 for Angus and 0.54 days for Hereford cattle.

The effect of previous calving date on calving interval was greater than the effect of previous calving date on present calving date. This is to be expected, since calving interval is essentially a function of previous calving date. This suggests that $\mathrm{CD}$ is a more preferable trait than $\mathrm{CI}$ for restricted calving seasons.

Table 5 shows the heritabilities $\left(\mathrm{h}^{2}\right)$ for and genetic correlations $\left(\mathrm{r}_{\mathrm{g}}\right)$ between CI, CD, CDP and AFC. Heritability estimates are presented on the diagonal (bold) while genetic correlations are above the diagonal. With the exception of AFC, heritabilities for the other traits were very low.

Table 5 Heritabilities and genetic correlations for reproductive traits

\begin{tabular}{lllll}
\hline Trait & CI & CD & CDP & AFC \\
\hline CI & $\mathbf{0 . 0 1}$ & 0.75 & 0.79 & -0.03 \\
CD & & $\mathbf{0 . 0 4}$ & 0.98 & 0.09 \\
CDP & & & $\mathbf{0 . 0 6}$ & 0.08 \\
AFC & & & & $\mathbf{0 . 4 0}$ \\
\hline
\end{tabular}

The heritability for CI corresponds with those found in the literature. Koots et al. (1994) also reported a mean $\mathrm{h}^{2}$ of 0.01 for CI (based on three estimates), while López de Torre \& Brinks (1990) found $\mathrm{a} \mathrm{h}^{2}$ of 0.02 for CI. The $\mathrm{h}^{2}$ estimates of 0.04 for $\mathrm{CD}$ also correspond with those found in the literature. Koots et al. (1994) reported a mean $h^{2}$ of 0.08 for CD (based on seven estimates), while Meacham \& Notter (1987), López de Torre \& Brinks (1990) and Rege \& Famula (1993) obtained higher $\mathrm{h}^{2}$ estimates of 0.16, 0.17 and 0.16 , respectively.

Notter (1988), Meyer et al. (1990), Ponzoni \& Gifford (1994) and Johnson \& Bunter (1996) emphasised the need to include all cows in the analysis, including cows that failed to calve during a restricted breeding season (non-calvers) for valid genetic evaluation of CD and variance component estimation. Biased estimates are obtained if data on open cows are omitted, as the results will not include the most genetically inferior and, therefore, potentially most informative animals (Notter, 1988). Heritability estimates obtained when open cows are excluded are expected to be biased downwards, thus suggesting that useful amounts of genetic variation for female fertility may exist (Notter, 1988). This requires that all non-calvers be assigned a penalty score value, which would allow their inclusion in the analysis. However, penalty values must be calculated in such a way that they will not bias cows which did calve (MacGregor, 1997). The procedure proposed by Notter (1988) and applied by both Buddenberg et al. (1990) and Meyer et al. (1990) used threshold theory to calculate penalty values of non-calvers. Ponzoni \& Gifford (1994) applied the procedure 
of Meyer et al. (1990). They found that the projected penalty values fell within the calving period, and consequently assigned the same value of 390 days to all non-calvers. Johnson \& Bunter (1996) found that this method produced a penalty value that was lower than $8 \%$ of all cows that calved in a specific year. Johnson \& Bunter (1996) concluded that this result was unsatisfactory, as some calvers would be unfairly compared with non-calvers. Since few cows are concurrently at the same stages of their reproductive cycles, and since the breeding season may not start at the same time each year, a single penalty value for all noncalvers may be undesirable as it would fail to simulate the actual herd situation. Most cows would eventually mate and calve if a restricted breeding period was not enforced (MacGregor, 1997).

Three methods for assigning a predicted value to non-calvers were also investigated by Johnston \& Bunter (1996). The first method (P360) assigned a value of 360 days to all non-calvers, and was described by Schneeberger et al. (1991). Johnston \& Bunter (1996) showed that P360 did not produce a satisfactory predicted value for non-calvers because there were cows that calved with a CD higher than 360 days. The other two methods identify a projected value that is assigned to each non-calver within a joining management group (i.e. the last calver within the group), and a constant number of days were added to this record to generate the projected value for all non-calvers. The two constants tested were plus 21 (P21) and 42 days (P42). MacGregor (1997) investigated two methods for assigning a predicted value to non-calvers. The first method involved establishing the relationship between present calving date and previous calving date by means of regression analysis. This was done by estimating the regression coefficient of present calving date on previous calving date, excluding all non-calvers. Each non-calver was then assigned a present calving date value based on an own previous calving date. In order to ensure that non-calvers received the longest calving days, 21 or 42 days were added to the value calculated from the regression. The second procedure was the P21 method that was described by Johnston \& Bunter (1996). Johnston \& Bunter (1996) and MacGregor (1997) suggested the P21 method because this method of adding a fixed number of days to the last calving date of calvers to calculate a penalty-calving-date value for non-calvers was successful in assigning a meaningful value to non-calvers. Therefore, P21 was also used in this study.

The $\mathrm{h}^{2}$ estimate for CDP of 0.06 is somewhat lower then the heritabilities found in the literature. Buddenberg et al. (1990) assigned a penalty score for CD to all non-calvers and obtained $a h^{2}$ estimate for $\mathrm{CD}$ in first calvers of 0.39. The majority of $\mathrm{h}^{2}$ estimates for these traits found in the literature were estimated using unitrait analyses, and this could be the reason for the higher $\mathrm{h}^{2}$ found in the literature, especially for CDP, compared to this study. Although the heritabilities obtained for CD and CDP are both low, CDP heritability was slightly higher than the heritability for $\mathrm{CD}$. The heritability for CD would be expected to be biased downwards (Notter, 1988) because of the exclusion of all open cows. The assignment of a penalty score may be a way to increase the heritability of $C D$ and to ensure a less biased measurement for reproductive performance.

The genetic correlation of 0.75 between $\mathrm{CD}$ and CI suggests that selection for an earlier CD would decrease CI. The high positive genetic correlation between CI and CD confirm the positive regression of CI on CD. The same applies to the correlation of 0.79 between CI and CDP. The high genetic correlation of 0.98 between CD and CDP suggests that these two traits are, in effect, the same trait. Although the $\mathrm{h}^{2}$ for both CI and CD was low, CD is preferred to CI because of the high negative correlation between CI and PCD (previous calving date) and other disadvantages associated with CI as discussed by Bourdon \& Brinks (1983), Buddenberg et al. (1990), Lòpez de Torre \& Brinks (1990), Marshall et al. (1990) and MacGregor (1995).

The $\mathrm{h}^{2}$ of 0.40 for AFC found in this study corresponds to most other estimates found in the literature. Kassab (1995), Singh et al. (1996) and Magana \& Segura (1997) obtained $\mathrm{h}^{2}$ values for AFC of 0.46, 0.36 and 0.46 , respectively. It therefore seems to be possible to change age at first calving through selection. However, Koots et al. (1994) reported a mean $\mathrm{h}^{2}$ of 0.06 for AFC. Singh et al. (1996) found a $\mathrm{r}_{\mathrm{g}}$ of 0.68 between AFC and CI. The $\mathrm{r}_{\mathrm{g}}$ values found in this study between AFC and CI, and between AFC and CDP were very low and were of limited genetic value.

Because of the repeatable nature of CI, CD and CDP, a repeatability model was fitted to these reproductive traits. Table 6 shows the repeatability estimates of the traits when traits were considered as traits of the dam. 
Table 6 Repeatability of reproductive traits

\begin{tabular}{lc}
\hline Trait & Repeatability \\
Calving interval & 0.07 \\
Calving date & 0.12 \\
Calving date with penalty scores & 0.13 \\
\hline
\end{tabular}

The repeatabilities obtained for CI, CD and CDP correspond to those found in the literature. For CD, Harwin et al. (1969), Lesmeister et al. (1973), Baily et al. (1985) and Rege and Famula (1993) reported repeatabilities of 0.14, 0.10, 0.12 and 0.23, respectively. Lindley et al. (1958), Plasse et al. (1966), Schalles \& Marlowe (1969) and Baily et al. (1985) obtained repeatability estimates for CI of 0.06, 0.03, 0.02 and -0.05 , respectively. Repeatabilities for CD or CDP therefore seem to be higher than those for CI. These low repeatabilities were expected because of the low heritabilities that were obtained in this study. This suggests that if a dam calves early in a calving season it does not necessarily mean that she will calve early in the subsequent calving season, and suggests that environment plays a greater role in reproduction traits.

\section{Conclusions}

In general, the heritabilities for all reproductive traits with the exception of AFC were low. However, selection for AFC would probably lead to animals that would be sexually mature at a younger age, but would be predisposed to calving difficulties.

Although the $\mathrm{h}^{2}$ estimates for both CI and CD were low, CD is preferred to CI because of the negative regression coefficient of CI on PCD. Heritabilities, genetic correlations and repeatabilities of CD and CDP obtained in this study suggest that CD and CDP are the same trait. Therefore, selection for CDP does not provide any additional advantage over selection for $\mathrm{CD}$. No unfavourable genetic correlations were identified in this analysis and it seems that $\mathrm{CD}$ is a suitable indicator trait for reproductive performance. The use of multitrait analyses in reproductive traits should become a more applied practice. It should be an essential part of analysing reproductive data, especially where selection indices for genetic improvement of reproduction are relevant.

\section{Acknowledgement}

The authors are grateful for the use of the data of the Johannesburg Metropolitan Council. Thanks in particular to Roger Wood.

\section{References}

Baily, D.W., Brinks, J.S. \& Bourdon, R.M., 1985. Repeatability estimates of beef cow reproductive traits by degree of adjacency. Proc. West. Sec. Am. Soc. Ani. Sci. 36, 26.

Bourdon, R.M. \& Brinks, J.S., 1983. Calving date versus calving interval as a reproductive measure in beef cattle. J. Anim. Sci. 57, 6.

Buddenberg, B.J., Brown, C.J. \& Brown, A.H., 1990. Heritability estimates of calving date in Hereford cattle maintained on range under natural mating. J. Anim. Sci. 68, 70.

Fahmy, M.H., Lalande, G. \& Hidiroglou, M., 1971. Reproductive performance and growth of Shorthorn puremated and crossmated cows. Anim. Prod. 13, 7.

Frazier, E.L., Sprott, L.R., Sanders, J.O., Dahm, P.F., Crouch, J.R. \& Turner, J.W., 1999. Sire marbling score expected progeny difference and weaning weight maternal expected progeny difference associations with age at first calving and calving interval in Angus beef cattle. J. Anim. Sci. 77, 1322.

Groeneveld, E., 1998. VCE4 Version 4.2.5 User's Guide and Reference Manual, Mariensee, Germany.

Harwin, G.O., Lamb, R.D. \& Bischop, J.H.R., 1969. Some factors affecting reproductive performance in beef females. Anim. Breed. Abstr. 37, 606.

Johnson, D.J. \& Bunter, K.L., 1996. Days to calving in Angus cattle: Genetic and environmental effects and covariance with other traits. Livest. Prod. Sci. 45, 13.

Kassab, M.S., 1995. Factors affecting some performance traits in Friesian cattle. Alexandria J. Agric. Res. 40,65 .

Koots, K.R., Gibson, J.P. \& Wilton, J.W., 1994. Analyses of published genetic parameters estimates for beef production traits. 1. Heritability. Anim. Breed Abst. 62, 309. 
Lesmeister, J.L., Burfening, P.J. \& Blacwell, R.L., 1973. Date of first calving in beef cows and subsequent calf production. J. Anim. Sci. 36, 1.

Lindley, C.E., Earley, G.T., Whatley, J.A. \& Chambers, D., 1958. A study of the reproductive performance of a purebred Hereford herd. J. Anim. Sci. 17, 336.

Lishman, A.W., Lyle, A.D., Smith, V.W. \& Botha, W.A., 1984. Conception rate of beef cows and growth of sucking calves as influenced by date of calving and supplementary feeding. S.Afr.J.Anim.Sci. 14,10.

Lòpez de Torre, G \& Brinks, J.S., 1990. Some alternatives to calving date and interval as measures of fertility in beef cattle. J. Anim. Sci. 68, 2650.

MacGregor, R.G., 1995. Evaluation of calving date and calving interval as measures of reproductive efficiency in beef cows. J. S. Afr. Vet. Assoc. 66, 235.

MacGregor, R.G., 1997. Evaluation of methods of measuring reproduction and production in beef cows. $\mathrm{PhD}$ Thesis. Univ. of Pretoria, South Africa.

Magana, J.G. \& Segura, J.C., 1997. Heritability and factors affecting growth traits and age at first calving of zebu beef heifers in South-Eastern Mexico. Trop. Anim. Health Prod. 29, 185.

Marshall, D.M., Minqiang, W. \& Freking, B.A., 1990. Relative calving date of first-calf heifers as related to production efficiency and subsequent reproductive performance. J. Anim. Sci. 68, 1812.

Meacham, N.S. \& Notter, D.R., 1987. Heritability estimates for calving date in Simmental cattle. J. Anim. Sci. 64, 701.

Meaker, H.J., Coetsee, T.P.N. \& Lishman, A.W., 1980. The effects of age at first calving on the productive and reproductive performance of beef cows. S. Afr. J. Anim. Sci. 10, 105.

Meyer, K., Hammond, K., Parnell, P.F., Mackinnon, M.J. \& Sivarajasingam, S., 1990. Estimates of heritability and repeatability for reproductive traits in Australian beef cattle. Livest. Prod. Sci. 25, 15.

Morris, C.A., 1984. Calving dates and subsequent intercalving intervals in New Zealand beef herds. Anim. Prod. 39, 51.

Morris, C.A., \& Cullen, N.G., 1988. Oestrus and reproductive performance of late calving beef cows. N.Z.J. of Agric.Res. 31, 395.

Notter, D.R., 1988. Evaluating and reporting reproductive traits. Proc. of the Beef Improvement Federation Research Symposium and Annual Meeting, Alburquerque, New Mexico. pp. 21-42.

Nunez-Dominguez, R., Cundiff, L.V., Dickerson, G.E., Gregory, K.E. \& Kock, R.M., 1991. Lifetime production of beef heifers calving first at two vs three years of age. J. Anim. Sci. 69, 3467.

Paterson, A.G., 1981. Factors affecting post weaning growth and reproduction of crossbred cattle under an intensive production system. D.Sc.Agric. Thesis. Univ. of Pretoria, South Africa.

Plasse, D., Koger, M., \& Warwick, A.C., 1966. Length of calving interval and time of conception in relation to calving and beginning of the mating season in four herds of purebred Brahman cows in Florida. Anim. Breed. Abstr. 34, 50.

Ponzoni. R.W. \& Gifford, D.R., 1994. Reproductive and some peri-natal variables in a mixed breed beef cattle herd. J. Anim. Breed. Genet. 111, 52.

Rege, J.E.O. \& Famula, T.R., 1993. Factors affecting calving date and its relationship with production traits of Hereford dams. Anim. Prod. 57, 385.

SAS Institute Inc., 1993, SAS/STAT Users Guide, Version 6, Vol.1, $4^{\text {th }}$ ed. SAS Institute Inc., Cary, North Carolina.

Schalles, R.R. \& Marlowe, T.J., 1969. Reproductive patterns in a herd of Angus cows. Anim. Breed. Abstr. $37,52$.

Schneeberger, M., Tier, B. \& Hammond, K., 1991. Introduction the third generation of BEEFPLAN and GROUP BEEFPLAN. Proc. $9^{\text {th }}$ Conf. Aust. Assoc. Anim. Breed. Genet., Melbourne, Australia. pp. 194-199.

Singh, M., Tomar, S.P.S., Singh, R.V. \& Manglik, V.P., 1996. Studies on genetic and non- genetic factors influencing reproduction parameters in crossbred cows. Indian J. Anim. Res. 30, 65.

Skrypzeck, H. , Schoeman, S.J. \& Jordaan., G.F., 2000. Estimated crossbreeding parameters in a multibreed cattle crossbreeding project. S. Afr. J. Anim. Sci. 30, 193.

Smith, B.A., Brinks, J.S. \& Richardson, G.V., 1989. Estimation of genetic parameters among reproductive and growth traits in yearling heifers. J. Anim. Sci. 67, 2886.

Toelle, V.D. \& Robison, O.W., 1985. Estimation of genetic correlations between testicular measurements and female reproductive traits in cattle. J. Anim. Sci. 60, 89. 
(C) South African Society of Animal Science

Van der Merwe, P.S. \& Schoeman, S.J., 1995. Effect of early calving of Simmentaler heifers under an extensive management system. S. Afr. J. Anim. Sci. 25, 36. 